\title{
RELAÇÃO ENTRE A CALCIFICAÇÃO DO CANINO INFERIOR E A MATURAÇÃO ÓSSEA EM CRIANÇAS CARDIOPATAS E NÃO CARDIOPATAS.
}

Miguel Angelo da CUNHA NETO; Joanna Gomes da CONCEIÇÃO; Cristiane dos Santos SAMPAIO; Mariana Rangel de Azevedo LOPES; Thais Macedo SOARES.

O conhecimento dos estágios de maturação das crianças é importante para o planejamento do tratamento ortodôntico. O objetivo do estudo foi avaliar a relação entre a calcificação do canino inferior e a maturação óssea em crianças cardiopatas e não cardiopatas. A amostra constitui-se por 111 crianças entre 6,75 e 12,33 anos, 72 cardiopatas e 39 não cardiopatas, atendidas no setor de Cardiologia do HUPE. A calcificação do canino foi determinada na radiografia panorâmica através do método de Demirjian. A avaliação da maturação óssea foi obtida pelo método de Singer, observando a ossificação dos ossos da mão e punho. Houve uma alta correlação entre maturação óssea e calcificação do canino $(r=0,69)$. Encontrou-se o estágio de maturação óssea I (precoce) em $100 \%$ dos casos de calcificação C, $88,9 \%$ de calcificação D e $68,8 \%$ de calcificação E. Entretanto, $71 \%$ dos casos com calcificação $F$ já se apresentavam no estágio de maturação óssea II (pré-puberal). Não foram encontradas diferenças significantes entre presença de cardiopatia com calcificação do canino inferior nem com maturação óssea. Observou-se neste estudo uma alta correlação entre a calcificação do canino inferior e a maturação óssea, onde $71 \%$ dos casos com estágio $\mathrm{F}$ de calcificação de canino apresentam-se em fase de crescimento prépuberal. 